\title{
Pro-inflammatory endothelial cell dysfunction is associated with intersectin-1s down-regulation
}

\author{
Sunit Singla ${ }^{1}$, Dan Predescu ${ }^{1,2}$, Cristina Bardita ${ }^{2}$, Minhua Wang ${ }^{2}$, Jian Zhang ${ }^{2}$, Robert A Balk and \\ Sanda Predescu $u^{1,2^{*}}$
}

\begin{abstract}
Background: The response of lung microvascular endothelial cells (ECS) to lipopolysaccharide (LPS) is central to the pathogenesis of lung injury. It is dual in nature, with one facet that is pro-inflammatory and another that is cyto-protective. In previous work, overexpression of the anti-apoptotic BCl- $\mathrm{X}_{\mathrm{L}}$ rescued ECs from apoptosis triggered by siRNA knockdown of intersectin-1s (ITSN-1s), a pro-survival protein crucial for ECs function. Here we further characterized the cyto-protective EC response to LPS and pro-inflammatory dysfunction.
\end{abstract}

Methods and Results: Electron microscopy (EM) analyses of LPS-exposed ECs revealed an activated/dysfunctional phenotype, while a biotin assay for caveolae internalization followed by biochemical quantification indicated that LPS causes a 40\% inhibition in biotin uptake compared to controls. Quantitative PCR and Western blotting were used to evaluate the mRNA and protein expression, respectively, for several regulatory proteins of intrinsic apoptosis, including ITSN-1s. The decrease in ITSN-1S mRNA and protein expression were countered by BCl-X $\mathrm{L}_{\mathrm{L}}$ and survivin upregulation, as well as Bim downregulation, events thought to protect ECs from impending apoptosis. Absence of apoptosis was confirmed by TUNEL and lack of cytochrome c (cyt c) efflux from mitochondria. Moreover, LPS exposure caused induction and activation of inducible nitric oxide synthase (iNOS) and a mitochondrial variant (mtNOS), as well as augmented mitochondrial NO production as measured by an oxidation oxyhemoglobin (oxyHb) assay applied on mitochondrial-enriched fractions prepared from LPS-exposed ECs. Interestingly, expression of myc-ITSN-1s rescued caveolae endocytosis and reversed induction of iNOS expression.

Conclusion: Our results suggest that ITSN-1s deficiency is relevant for the pro-inflammatory ECs dysfunction induced by LPS.

\section{Background}

Severe sepsis is the leading clinical cause of lung injury [1]. No specific therapy currently exists for this critical illness, and efforts to reduce its burden have been limited by an incomplete understanding of the mechanisms of disease. Exposure of ECs to LPS is a widely used model for studying endothelial dysfunction in this syndrome [2]. The endothelial response to LPS is dual in nature, with one facet that is pro-inflammatory and another that is cyto-protective $[2,3]$. NF- $\kappa \mathrm{B}$ and JNKmediated pathways engage ECs to actively participate and regulate the pro-inflammatory process in response to LPS by expression and release of damaging

\footnotetext{
* Correspondence: sanda_predescu@rush.edu

'Pulmonary and Critical Care Medicine, Rush University Medical Center, 1750

W. Harrison Street, 297 Jelke, Chicago, IL 60612, USA

Full list of author information is available at the end of the article
}

components such as iNOS, cytokines, adhesion molecules, and pro-coagulants [4-6]. This response has been alternatively referred to as the activated endothelial phenotype $[4,5]$. Much less is known however, with respect to the exact nature, regulation and timing of the cytoprotective aspect of the ECs response. A role of $\mathrm{Bcl}$ members $\mathrm{Bcl}-2$ and $\mathrm{Bcl}-\mathrm{X}_{\mathrm{L}}$ in potentially shielding the cells from their proapoptotic environment has been described [2,3]. In our previous work, overexpression of $\mathrm{Bcl}-\mathrm{X}_{\mathrm{L}}$ rescued lung ECs from apoptosis after siRNAmediated knockdown of ITSN-1s, a novel scaffold and regulator of the general endocytic machinery, as well as a critical protein for pro-survival signaling in ECs $[7,8]$. ITSN-1s deficiency caused severe EC dysfunction, decrease in caveolae number, structural alterations and dysfunction of mitochondria, generation of mitochondrial reactive oxygen species (ROS) and apoptosis [7].

C Biomed Central

(c) 2011 Singla et al; licensee BioMed Central Ltd. This is an Open Access article distributed under the terms of the Creative Commons Attribution License (http://creativecommons.org/licenses/by/2.0), which permits unrestricted use, distribution, and reproduction in any medium, provided the original work is properly cited. 
Similar observations of many of these phenomena in previous studies of LPS-induced endothelial dysfunction and the suggested role of $\mathrm{Bcl}-\mathrm{X}_{\mathrm{L}}$ in cyto-protection during inflammatory stress led us to consider ITSN-1s as a participant in either of these events.

Numerous lines of evidence have documented the considerable oxidative and nitrosative stress associated with lung injury in human patients, and potential pathways by which either may mediate endothelial barrier dysfunction have also been well described $[9,10]$. iNOS is known to be up-regulated in response to LPS in a variety of cells, including lung ECs [11]. The resultant increased NO production has the ability to potentially alter a large variety of cellular processes such as interendothelial junctional integrity and thereby, basal vascular permeability [9]. The selective inhibition of iNOS has significantly attenuated the ability of endotoxin to generate lung injury in several animal models [12,13]. Notably, loss of caveolin-1 (cav-1) expression and thus lack of caveolae endocytosis and transcytosis resulted in constitutive activation of eNOS, increased NO production and a microvascular hyperpermeability cav-1 -/- mouse phenotype [14]. Thus, in the current study, we sought to further characterize ECs dysfunction and the elements of the cyto-protective ECs response to LPS.

\section{Methods}

\section{Cell lines and reagents}

Human lung microvascular ECs were purchased from Lonza (Walkersville, Inc., MD). LPS from Escherichia coli 011:B4, calmodulin from bovine testes, tetrahydrobiopterin $\left(\mathrm{BH}_{4}\right)$, protease inhibitors cocktail, L-arginine and primers for qPCR were from Sigma-Aldrich (St. Louis, MO). Superoxide dismutase (SOD) from bovine erythrocytes was purchased from MP Biomedicals. Freeze dried $\mathrm{Hb}$ was from ICN Biomedicals. The In Situ Cell Death Detection Kit, Fluorescein was from Roche (Indianapolis, IN). Prolong Antifade Kit and neutrAvidin Alexa Fluor 594 were from Molecular Probes (Eugene, OR). EZ-Link Sulfo NHS-SS-Biotin was from Fisher Scientific (Hanover Park, IL). Streptavidin-HRP conjugated, MicroBCA (bicinchoninic acid) Protein Assay Reagent and Enhanced Chemiluminescent (ECL) Western Blotting Substrate were from Pierce (Rockford, IL). Specific antibodies (Abs) were obtained from the following sources: anti-Bcl- $\mathrm{X}_{\mathrm{L}} \mathrm{mAb}$, anti-NOS2 $\mathrm{pAb}$ from Santa Cruz Biotechnology (Santa Cruz, CA); anticyt c mAb from Calbiochem; anti-ITSN-1s mAb from BD Biosciences (San Jose, CA); anti-Bim pAbs from Millipore (Billerica, MA); anti-survivin pAbs from Novus Biologicals; Horseradish peroxidase (HRP)-conjugated reporters were from Cappel, Organon Teknika (Durham, NC).

\section{Endothelial Cell Culture and LPS treatment}

ECs were cultured at $37^{\circ} \mathrm{C}$ in $5 \% \mathrm{CO} 2$ in endothelial growth medium-2 obtained from Lonza and prepared according to manufacturer's instructions. Cells between the third and fifth passages were used for experiments. LPS (dry powder) was reconstituted in growth medium and applied over cells in a concentration of $1 \mu \mathrm{g} / \mathrm{ml}$ for a duration of up to 48 hours.

\section{Protein Extraction and Western blotting}

Control ECs or cells exposed to $1 \mu \mathrm{g} / \mathrm{ml}$ LPS in culture media were collected from culture dishes and washed with PBS. Cell pellets were lysed for $1 \mathrm{~h}$ at $4^{\circ} \mathrm{C}$ in 50 $\mathrm{mM}$ Tris $\mathrm{HCl}, \mathrm{pH} 8.0,150 \mathrm{mM} \mathrm{NaCl}, 1 \% \mathrm{NP}-40$, and protease inhibitors. For detection of phospho-Bim $\left(\right.$ Ser $\left.^{69}\right)$ levels, control and LPS-treated ECs were solubilized in kinase buffer $(20 \mathrm{mM}$ Tris $/ \mathrm{HCl}, \mathrm{pH} 7.4,150$ $\mathrm{mM} \mathrm{NaCl}, 0.1 \%$ Nonidet P-40, 1\% glycerol, $0.2 \mathrm{mM}$ sodium vanadate, $0.83 \mathrm{mM}$ benzamidine, $0.23 \mathrm{mM}$ phenylmethylsulfonyl fluoride, $0.5 \mu \mathrm{g} / \mathrm{ml}$ aprotinin, and 0.5 $\mu \mathrm{g} / \mathrm{ml}$ leupeptin). After centrifugation at $45000 \mathrm{rpm}$ for $45 \mathrm{~min}$ at $4^{\circ} \mathrm{C}$, the supernatants were collected and protein concentration determined by BCA with a bovine serum albumin standard. Equivalent protein amounts were subjected to SDS-PAGE and transferred to nitrocellulose membranes. The membranes were probed with anti-NOS2 pAb, anti-Bcl-X $\mathrm{L}_{\mathrm{L}} \mathrm{mAb}$, anti-ITSN-1 mAb, anti-Bim pAb, anti-survivin pAb, diluted in blocking buffer, (5\% milk/TBS). Immunoreactive bands were visualized with the appropriate HRP-conjugated Abs and ECL detection. Densitometry was performed with ImageJ v1.37 software.

\section{Internalization Assay}

Control and LPS-treated ECs, grown on plastic Petri dishes or coverslips were washed with ice-cold PBS and then incubated with $0.5 \mathrm{mg} / \mathrm{ml}$ cleavable biotin reagent as in $[15,16]$. Biotinylated cell surface proteins were internalized for $30 \mathrm{~min}$, at $37^{\circ} \mathrm{C}$. Biotinylated proteins still at the cell surface after $30 \mathrm{~min}$ were reduced with glutathione and the cells were further processed for morphological analysis or lysed for biochemical investigation. For biochemical studies, cells were lysed in TBS containing $2 \%$ Triton X-100, and the lysates were clarified by centrifugation for $30 \mathrm{~min}$, at $4^{\circ} \mathrm{C}, 40,000 \mathrm{rpm}$ in a TLA-45 Beckman rotor, to obtain a final supernatant expected to contain the internalized biotinylated proteins. The number of biotin molecules in the ECs lysates were quantified by ELISA as in [15]. Standard curves were generated using known concentrations of albuminbiotin. The average number of biotin molecules present in each cell lysate was determined at a series of decreasing concentrations from the linear part of the curve obtained by successively diluting a standard volume 
$(100 \mu \mathrm{l})$ from each lysate and normalized per mg total protein. To obviate any interference between the biotinylated proteins internalized via caveolae and biotin present in mitochondria [17], we evaluated the biotin content of mitochondria by ELISA applied on lysate prepared from control ECs, not subjected to biotinylation of cell surface proteins. Mitochondrial proteins comprise only $0.25 \times 10^{14}$ biotin molecule $/ \mathrm{mg}$ total protein, a value without statistical significance, when compared to the extent of biotin internalization via caveolae.

\section{Measurement of Transendothelial Electrical Resistance and paracellular permeability}

ECs were grown to confluence on gold electrode array plates available from Applied Biophysics, Inc., Troy, NY. Transendothelial electrical resistance (TER) was measured by an electrical cell-substrate impedance sensing system (Applied Biophysics, Inc.) as described in [18]. Briefly, the gold electrode plates were connected to a phase-sensitive lock-in amplifier and a 1 volt $4000 \mathrm{~Hz}$ AC signal was applied through a $1 \mathrm{M} \Omega$ resistor. Inphase voltage was measured and used to determine TER which was normalized to initial values. A decrease in TER during the experiment reflects loss of cell-cell adhesion.

\section{Transwell assay}

Transwell chambers with $.4 \mu \mathrm{m}$ pore filter inserts (BD Bioscience) were used. The inserts were coated overnight with $0.1 \%$ gelatin, at $37^{\circ} \mathrm{C}$. Cells were seeded in the upper compartment and grown for additional 3 days post-confluency. Then, cell monolayers were subjected to $1 \mu \mathrm{g} / \mathrm{ml}$ LPS for $6 \mathrm{~h}$, as an early time point, and $48 \mathrm{~h}$, the time point used for biotin assay for caveolae internalization. The last hour of LPS treatment, $1 \mathrm{mg} / \mathrm{ml} \mathrm{dini-}$ trophenylated (DNP)-BSA was added in the upper chamber. To quantify the transport, $500 \mu \mathrm{l}$ medium from the lower chamber were removed and subjected to ELISA, via anti-DNP Ab, as previously described $[19,20]$. All measurements were performed in triplicate and repeated three times. A standard curve was generated by diluting known concentration of DNP-BSA.

\section{Molecular cloning of ITSN-1s expression construct}

The full-length human ITSN-1s cDNA fragment $(3,660$ bp) was generated by PCR amplification from ITSN-1s cDNA (gift from Suzana la Luna, Center for Genomic Regulation, UPF, and Centro de Investigacion Biomedica en Red de Enfermedades Raras, Barcelona, Spain) with high-fidelity PCR enzyme (New England Biolabs), using the following primer pair: ITSN1s_F269-BstBI: 5' AGTA TTCGAA CC ATG GCT CAG TTT CCA ACA CCT T 3'and ITSN1s_R3929-NheI: 5' CGTA GCTAGC TTG CTG GCT TGG GTC CAT GTC TG 3'. The PCR products of the full-length ITSN-1s were digested with restriction enzyme BstBI and Nhe I (New England Biolabs) and purified (Qiagen purification kit), then cloned into a expression vector, pReiver-M10a (GeneCopoeia) at BstBI-NheI sites using T4 ligase (New England Biolabs). The ligation products were transformed into $E$. coli strain Top10 (Invitrogen). Dozens of transforming colonies were selected and subjected to PCR to identify the colonies with the ITSN-1s inserts using the same sequencing primer pair. The plasmid DNA was extracted from 6 selected growing clones bearing the ITSN-1s insert and was verified with correct restriction enzyme (BstBI and Nhe I) sites. Finally, one of them, CS-Z3999_ITSN1s \#16 was selected for maxi-preparation of plasmid DNA, sequencing confirmation of the entire integrity of the full-length cDNA of ITSN-1s in frame in the vector and used for transfection of ECs. All transfections were performed using FuGENE 6, according to the manufacturer's instructions.

\section{Mitochondrial isolation and measurement of iNOS activity Preparation of Mitochondrial fractions}

EC monolayers grown on Petri dishes were washed three times with ice-cold PBS, $\mathrm{pH} 7.4$, and collected by gentle scraping and centrifugation at $500 \times \mathrm{g}$ for 10 min. The cell pellets were resuspended in isolation buffer containing $250 \mathrm{mM}$ sucrose, $40 \mathrm{mM}$ Tris/ $\mathrm{HCl}, \mathrm{pH}$ 7.5, $10 \mathrm{mM} \mathrm{MgCl}_{2}, 2 \mathrm{mM} \mathrm{CaCl}, 1 \mathrm{mM}$ phenylmethylsulfonyl fluoride, $15 \mu \mathrm{g} / \mathrm{ml}$ leupeptin as in [7]. They were kept on ice for $30 \mathrm{~min}$ and then disrupted with 40 strokes in a glass Dounce homogenizer. This was followed by centrifugation at $800 \times \mathrm{g}$ at $4^{\circ} \mathrm{C}$ for 10 minutes to remove unbroken cells, nuclei, and debris. The postnuclear supernatant was then subjected to centrifugation at $22,000 \times \mathrm{g}$ at $4^{\circ} \mathrm{C}$ for 10 minutes to isolate the mitochondrial pellet. The mitochondrial pellet was lysed in 50 mM HEPES, pH 7.4, 1\% Nonidet P-40, 10\% glycerol, $1 \mathrm{mM}$ EDTA, $2 \mathrm{mM}$ dithiothreitol, and protease inhibitors.

\section{Spectrophotometric determination of iNOS activity}

NO production was assayed by utilizing its reaction with oxyHb to produce the optically distinct methemoglobin (metHb) as previously described [21]. Briefly, unlysed mitochondrial pellets were resuspended in hypo-osmotic solution by adding 2 volumes of icechilled water containing a protease inhibitor cocktail. This was followed by sonication at $100 \mathrm{~W}, 50 \%$ duty cycle, and $75 \mathrm{~s}$. Isolation buffer of twice the concentration used for the preparation of mitochondrial fractions was then added in the same amount as water used in the previous step. The suspension was centrifuged at $10,000 \times \mathrm{g}$ at $4^{\circ} \mathrm{C}$ for $10 \mathrm{~min}$. The supernatant contained broken mitochondria and was used for the subsequent reaction. 
Commercially available $\mathrm{Hb}$ contains a mixture of oxyHb and metHb which must be fully reduced to obtain pure oxyHb for the reaction. This was accomplished by the Dixon and McIntosh method [22]. Briefly, $0.2 \mathrm{ml}$ of $0.1 \mathrm{~g} / \mathrm{ml}$ sodium dithionite was added to a prepacked Sephadex column. When all of the dithionite had completely entered the gel bed, $1 \mathrm{ml}$ of $50 \mathrm{mg} / \mathrm{ml}$ $\mathrm{Hb}$ was added. As the $\mathrm{Hb}$ passed through the dithionite zone, its color changed to purple and it then changed to an orange-red color as it left the dithionite. This was collected and the concentration measured spectrophotometrically using $\varepsilon_{415} \mathrm{~nm} 131.0 \mathrm{mM}^{-1} \mathrm{~cm}^{-1}$.

Dilution or oxidation of NOS substrates or cofactors during the preparation of broken mitochondria requires the presence of $5 \mu \mathrm{g} / \mathrm{ml}$ calmodulin, $50 \mu \mathrm{M}$ L-arginine, $10 \mu \mathrm{M}$ tetrahydrobiopterin $\left(\mathrm{BH}_{4}\right)$, and $1 \mathrm{KU} / \mathrm{ml} \mathrm{SOD}$ in the assay medium. These substrates were added to $1 \mathrm{~mL}$ of $100 \mathrm{mM}$ HEPES, $\mathrm{pH} 7.1$ in a cuvette followed by 4 $\mu \mathrm{M}$ oxyHb. $30 \mu \mathrm{g}$ of mitochondrial protein was added and the optical density continuously recorded for five minutes at a wavelength of $401 \mathrm{~nm}$. NO formation was quantified using $\varepsilon_{401 \text { (metHb-oxyHb) }}$ of $49 \mathrm{mM}^{-1} \mathrm{~cm}^{-1}$.

\section{Terminal Deoxynucleotidyltransferase-mediated dUTP Nick End Labeling (TUNEL) Assay}

Control ECs and cells exposed to LPS $(1 \mu \mathrm{g} / \mathrm{ml})$ for up to $48 \mathrm{~h}$ were washed in PBS and then fixed and permeabilized in methanol for $7 \mathrm{~min}$, at $-20^{\circ} \mathrm{C}$. The TUNEL reaction mixtures (label and enzyme solutions) were prepared as directed by the manufacturer. It was applied over EC monolayers for $60 \mathrm{~min}$, at $37^{\circ} \mathrm{C}$, under dark and humid conditions. Monolayers exposed to label solution only were used as negative controls. The cells were washed and coverslips mounted using the Prolong Antifade kit. Fluorescence microscopy with an excitation wavelength of $488 \mathrm{~nm}$ identified TUNEL-positive cells.

\section{qPCR studies}

Cells were lysed using the Qiagen QIAShredder homogenizer and the RNA was isolated using the Qiagen RNeasy Mini RNA isolation kit as per the manufacturer's instructions. cDNA was generated with the highcapacity cDNA RT kit by Applied Biosystems following the manufacturer's protocol. Amplifications were carried out using the following primers: ITSN-1s (5'CAGGCTTGAAAGTCCTCAAAG-3', 5'-GGTGATCATGCTGGAAGTCA-3'), Bim (5'-TCCCTGCTGT CTCGATCCTC-3', 5'-GGTCTTCGGCTGCTTGGTAA3'), Bcl- $\mathrm{X}_{\mathrm{L}}$ (5'-CTGTCGGTGGAAAGCGTAGA-3', 5'TGCTGCATTGTTCCCATAGAG-3'), Survivin (5'AAGAACTGGCCCTTCTT GGA-3', 5'-CAACCGGACGAATGCTTTT-3'). mRNA levels were quantified by real-time monitoring of the products of the cDNAs PCR with SYBR Green fluorescent dye. Cyclophilin was used as internal control.

\section{Electron microscopy}

Control and LPS-treated cells were subjected to standard EM procedure [15]. Briefly, EC monolayers were fixed in $1.5 \%$ glutaraldehyde in $0.1 \mathrm{M}$ sodium cacodylate buffer, $\mathrm{pH}$ 7.4, containing $5 \%$ sucrose for $30 \mathrm{~min}$ at RT. After washing in the same buffer the cells were postfixed in Palade's $1 \%$ osmium tetroxide for $1 \mathrm{~h}$ on ice, stained with Kellenberger buffer, dehydrated in graded ethanol, and embedded in Epon at $60^{\circ} \mathrm{C}$.

\section{Results and discussion \\ LPS exposure causes an activated/dysfunctional ECs phenotype}

It is well documented that ECs are active participants in and regulators of inflammatory processes such as severe bacterial infection $[4,23]$. However, there is still significant debate on the extent of vascular dysfunction that is due to the direct effects of bacterial products such as LPS on the endothelium. Thus, in this study we evaluated by highresolution EM the morphological changes caused by direct LPS exposure on human lung microvascular ECs. Confluent ECs monolayers were treated with $1 \mu \mathrm{g} \mathrm{LPS} / \mathrm{ml}$, for 48 $\mathrm{h}$, and then subjected to standard EM procedure as in [7]. Detailed examination revealed disrupted interendothelial junctions (IEJs), as illustrated in Figure 1a, b, and increased accumulation of actin filaments at cell periphery (Figure $1 \mathrm{c}$ arrows), suggesting increased paracellular permeability, one of the first sign of endothelial activation in response to inflammation. Several cellular organelles such as Weibel-Palade bodies and Golgi show apparently normal morphology, but their number was significantly increased (Figure 1d, f, f1) by reference to control ECs. Golgi organelles were spread throughout the cell, while a swollen endoplasmic reticulum (Figure 1c), occupied the entire intracellular space, observations consistent with expression of pro-inflammatory/cytoprotective genes as well as the ER stress. Fragments of control ECs are shown for comparison, (Figure 2a, a1). Note that these cells maintain in culture their endothelial phenotype; in close proximity of the nucleus there are Golgi stacks and vesicles as well as two mitochondrial units showing well-organized cristae. A normal, unswollen endoplasmic reticulum is detected within the two mitochondrial units. Note also a WeibelPalade body by the basolateral plasma membrane. Caveolae, the main vesicular carriers of ECs, involved in the transport of plasma proteins and nutrients across the endothelium are open apically or basolaterally, apparently charging or discharging their load, (Figure $2 \mathrm{a} 1$ arrows). In LPS-treated ECs we have also frequently noted numerous small mitochondrial units. Large vacuoles, increased 

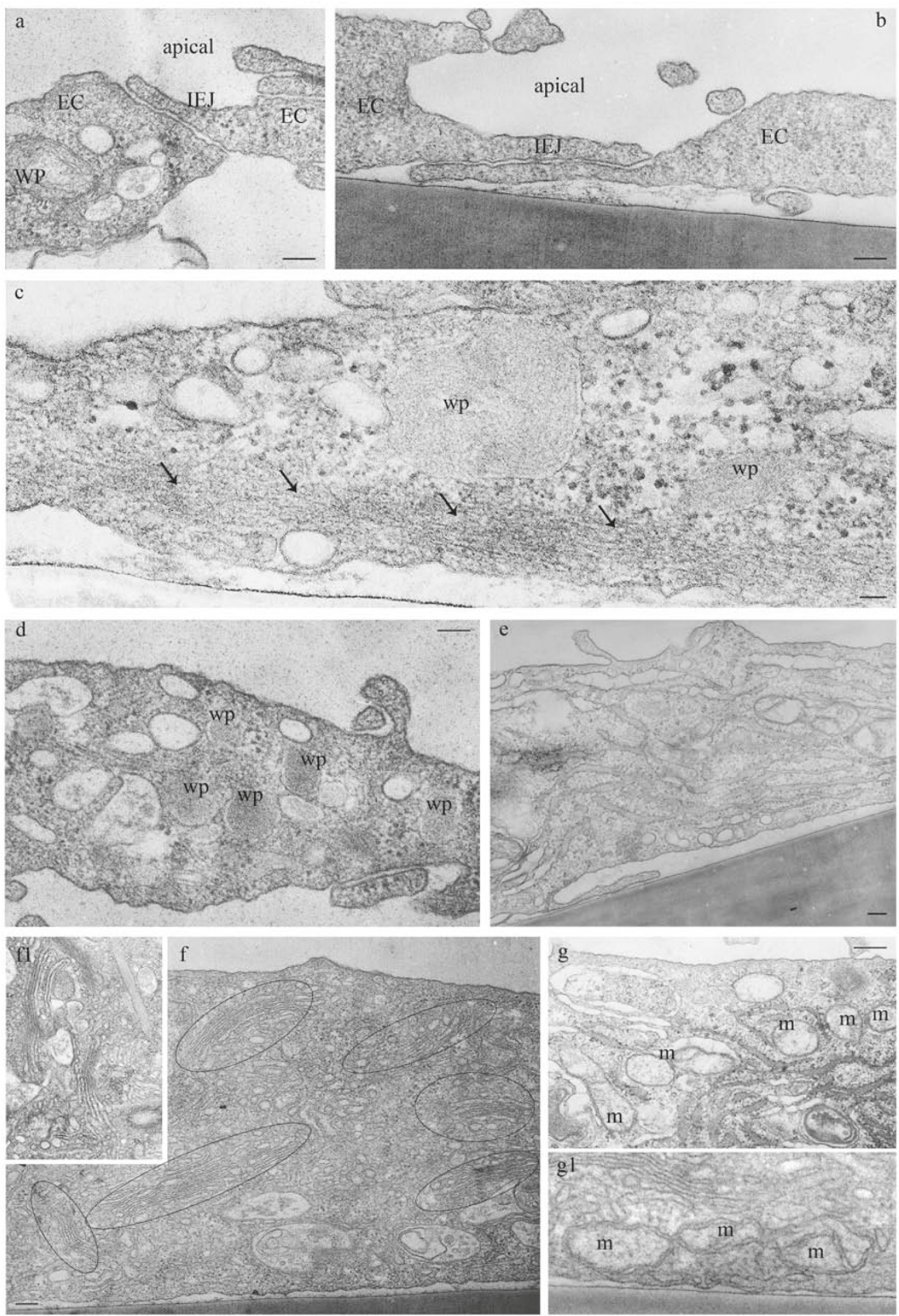

Figure 1 LPS exposure causes an activated/dysfunctional ECs phenotype (I). ECs exposed to $1 \mu \mathrm{g} / \mathrm{ml}$ LPS for 48 h show open IEJs, (a, b), increased accumulation of actin filaments at cell periphery (c, arrows), significant increase in the number of Weibel-Palade (wp) bodies (d) and Golgi (f, circled areas). An enlarged and widespread endoplasmic reticulum network and the presence of a dilated tubular system are shown in e; frequently, increase number of lysosomal (lys) units is observed (a, $\mathbf{d}, \mathbf{f})$. Panel $\mathbf{g}$ shows a segment of cultured lung microvascular ECs comprising increased number of mitochondrial units $(m)$, most of them with abnormal morphology. Note also the close association between ER and mitochondria. Frequently, mitochondria undergo a fission process (g1). Bars: 100 nm (a, b, d, e, f, g); 50 nm (c); 


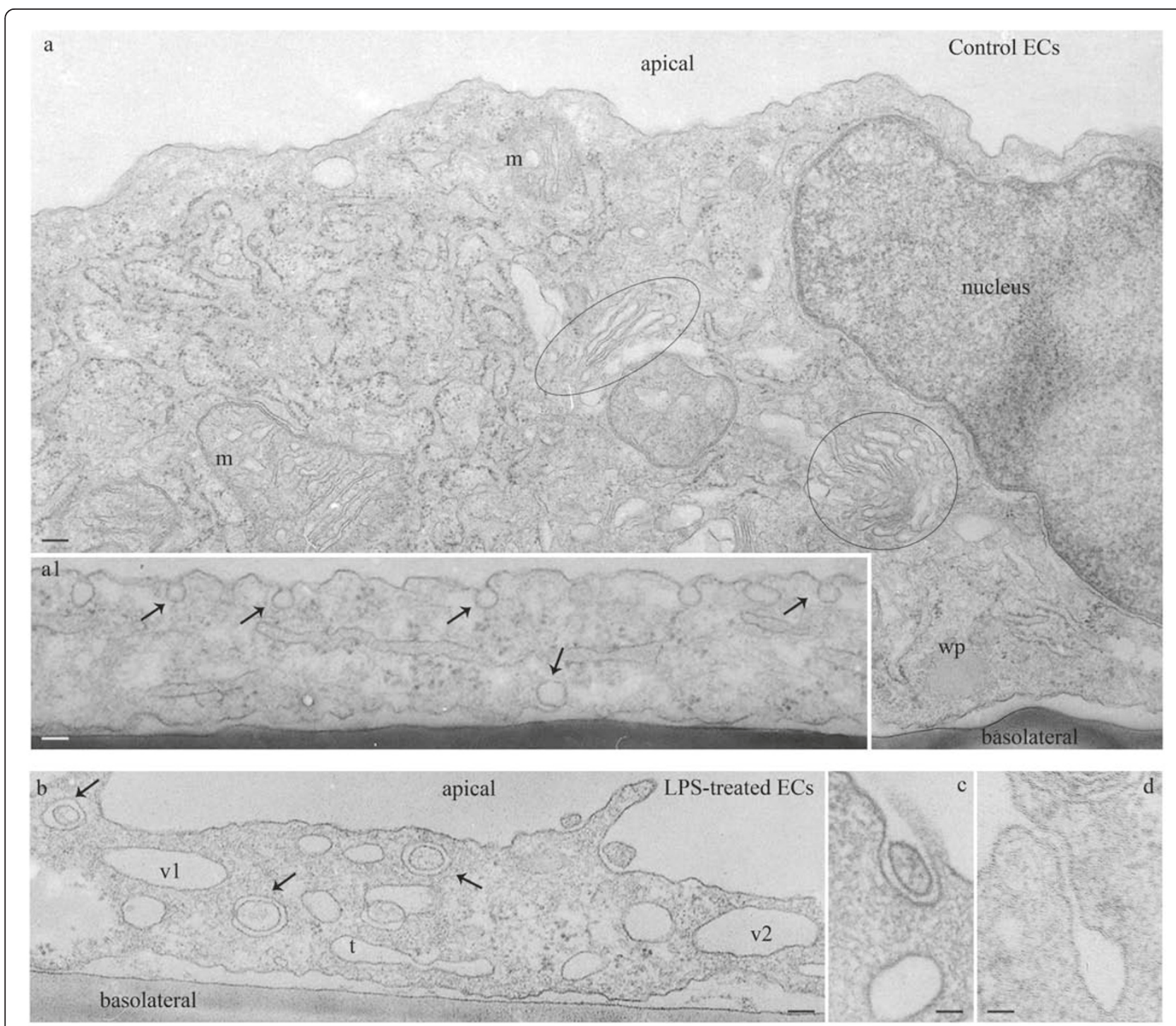

Figure 2 LPS exposure causes an activated/dysfunctional ECs phenotype (II). Fragments of control ECS show a normal endothelial phenotype: Golgi stacks and vesicles as well as two mitochondrial units with well-organized cristae (a), a wide endoplasmic reticulum network is located within the two mitochondrial units. Note also a Weibel-Palade (wp) body in close proximity of the basolateral plasma membrane. Caveolae are open apically or basolaterally, apparently charging or discharging their load, (a1, arrows). In panel $\mathbf{b}$, a fragment of an ECs subjected to $1 \mu \mathrm{g} / \mathrm{ml}$ LPS shows frequently large vacuoles ( 1 1, v2), membranous rings, (arrows) and tubules (t), within cytosol or open to the cell surface (c, d), suggestive of deficient endocytic transport. Bars: $50 \mathrm{~nm}(\mathrm{a}) ; 100 \mathrm{~nm}(\mathrm{a} 1) ; 70 \mathrm{~nm}(\mathrm{~b}) ; 40 \mathrm{~nm}(\mathbf{c}, \mathrm{d})$.

frequency of tubular structures and membraneous rings, (Figure 2b) some of them opened to the apical front of the cell (Figure 2c, d) are detected, suggesting impaired endocytosis and activation of alternative, non-conventional, transport pathways [24]. Altogether, these observations are consistent with an activated and dysfunctional EC phenotype.

\section{Endocytic dysfunction and a concomitant paracellular} hyperpermeability is a hallmark of the LPS-EC phenoytpe Since LPS signaling is regulated by caveolae endocytosis $[25,26]$ and since EM analysis revealed endocytic abnormalities in LPS-treated cells, we next used a biotin internalization assay as in $[15,16]$ to address if EC exposure to LPS affects caveolae endocytosis. This assay is a specific and reliable approach for addressing caveolae internalization in cultured ECs [15]. Caveolae-mediated uptake of biotinylated cell surface proteins is the dominant mechanism of internalization in ECs; the number of clathrin-coated vesicles in ECs is relatively small and their contribution to the internalization process is minor [27]. Briefly, control and LPS-exposed ECs were subjected to biotinylation of cell surface proteins, at $4^{\circ} \mathrm{C}$, using a cleavable biotin reagent. Then, cells were 
transferred to $37^{\circ} \mathrm{C}$, for $30 \mathrm{~min}$, to allow internalization of biotinylated proteins. The biotinylated proteins, still on the cell surface after $30 \mathrm{~min}$ were reduced with glutathione. Then, the cells were either lysed for biochemical quantification of LPS effects on caveolae internalization by enzyme-linked immunosorbent assay (ELISA) or subjected to neutrAvidin-Alexa Fluor 594 staining for morphological surveys by fluorescence microscopy. Biochemical quantification of the number of biotin molecules internalized by control and LPSexposed cells, Figure 3A indicated that in LPS-treated EC lysates, the number of biotin molecules was considerably smaller. A comparison of LPS-treated cells to controls shows an inhibition of 40\%, (Figure 3B). Morphological analyses with NeutrAvidin-Alexa Fluor 594 revealed in control cells a fine punctate pattern throughout the cytoplasm, suggestive of vesicular association, (Figure 4c1). Frequently, biotin accumulation in the perinuclear area was detected. In LPS-exposed cells the staining was limited (Figure 4c2); large fluorescent puncta within the cytosol and no biotin accumulation in the perinuclear area were observed, suggestive of impaired biotin internalization. The intercellular spaces are large, consistent with disruption of IEJs. Highly magnified controlled and LPS-exposed cells (boxed areas), are shown, (Figure 4c1.1, c2.1).

Since $1 \mu \mathrm{g} / \mathrm{ml}$ LPS exposure downregulates ITSN-1s expression and as a result transcellular transport is impaired, we next evaluated the status of paracellular permeability of ECs monolayers by measurements of TER, under the same conditions of LPS exposure. Monolayers of ECs grown on gold microlectrodes, three days post-confluency, were first stabilized for two hours to establish a linear TER baseline. Then, The stabilized monolayers were stimulated with LPS (Figure 5A, arrow) and TER was monitored over 24 hours, Figure $5 \mathrm{~A}$. A gradual decrease in the baseline barrier resistance was recorded for the first hours after LPS stimulation with a maximal decrease after $8 \mathrm{~h}$ and remaining in a plateau for the next $16 \mathrm{~h}$ hours. These data strongly suggest that LPS disrupts endothelial barrier and significantly increases the paracellular permeability of lung microvascular ECs. To get more insights on the extent of endothelial barrier dysfunction, we quantified the paracellular transport of dinitrophenylated albumin (DNP-BSA) using a transwell assay, as described under Methods. In brief, cells were seeded in the upper chamber and 3 days post-confluency, endothelial monolayers were subjected to $1 \mu \mathrm{g} / \mathrm{ml}$ LPS for $6 \mathrm{~h}$, as an early time point, and $48 \mathrm{~h}$, the time point used for biotin assay for caveolae internalization. In the last hour of LPS treatment, BSA-DNP was layered on top of EC monolayers to a final concentration of $1 \mathrm{mg} / \mathrm{ml}$. To quantify the transport, $500 \mu \mathrm{l}$ medium from the lower chamber were removed and subjected to ELISA, via DNP $\mathrm{Ab}$, as previously described $[19,20]$. As shown in Figure 5B, the permeability of the endothelial monolayer for the DNPBSA tracer were determined at a series of decreasing

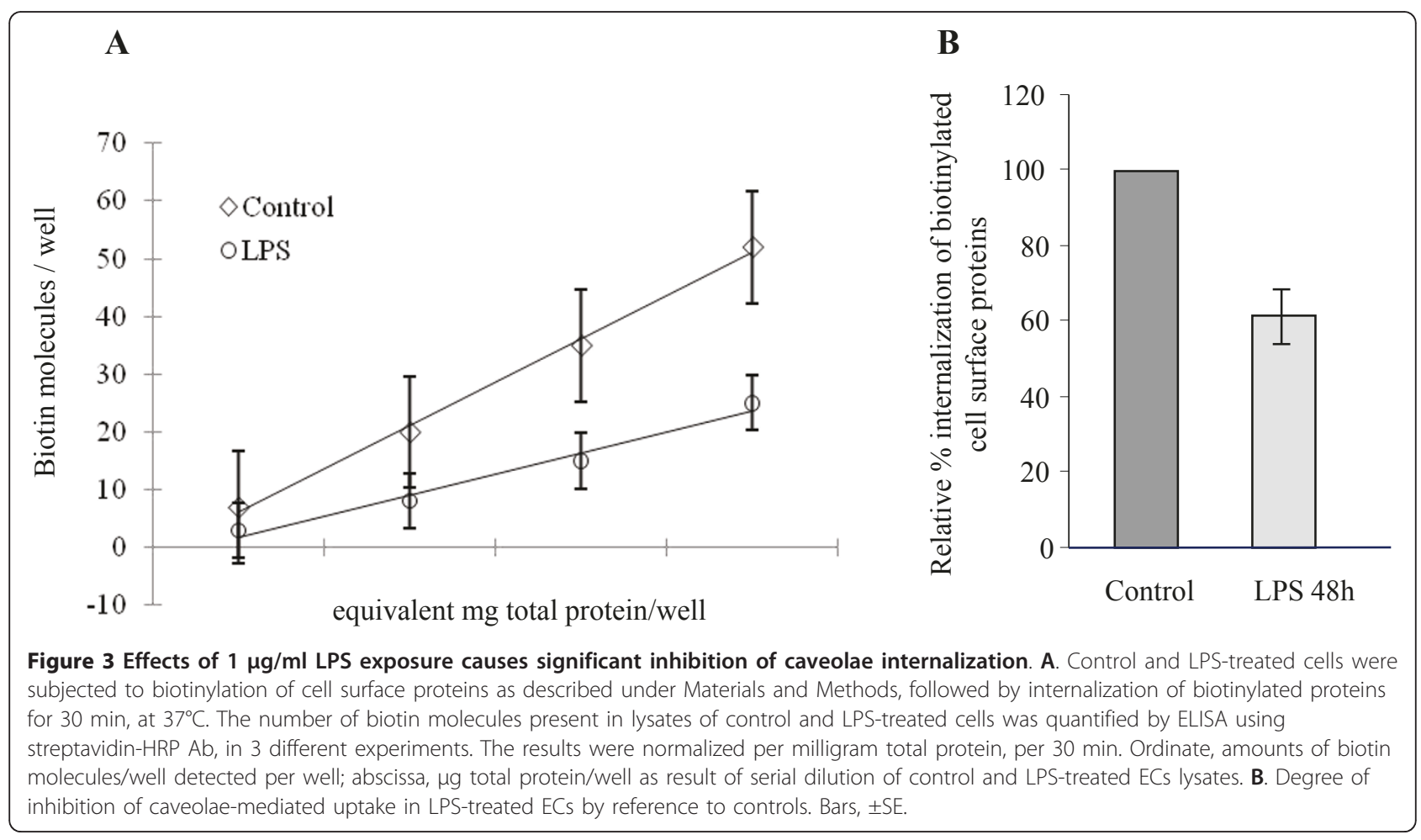



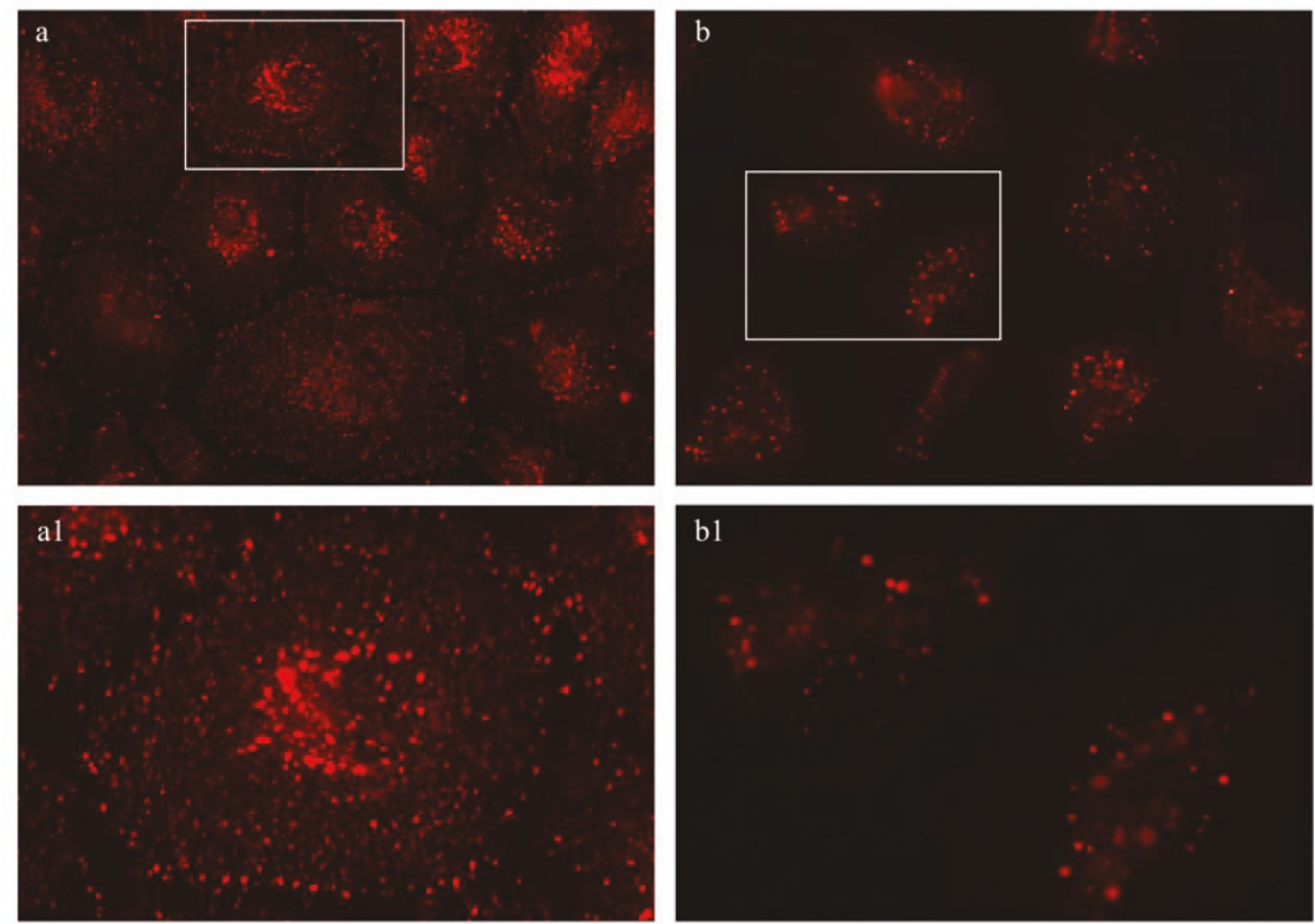

Figure 4 NeutrAvidin Alexa Fluor 594 staining demonstrates inhibition of caveolae internalization by $1 \mu \mathrm{g} / \mathrm{ml}$ LPS exposure. NeutrAvidin Alexa Fluor 594 staining of control ECs subjected to biotinylation of cell surface proteins followed by internalization assay, indicates a strong punctate pattern throughout the cytosol (c), with some accumulation in the perinuclear area. An enlarged ECs (boxed area in c) subjected to the internalization assay is shown in c1. ECs exposed to LPS and subjected to the internalization assay followed by neutrAvidin Alexa Fluor 594 staining (b, b1) show large fluorescent puncta within the intracellular space with no perinuclear accumulation. Bars: a, a1, b, b1 $20 \mu \mathrm{m}$.

concentration from the linear part of the curve obtained by serial dilution of a standard volume of growth media removed from the lower chamber. In the presence of LPS, the amounts of DNP-BSA crossing the monolayer were considerably higher than control levels. Measurements of DNP-BSA amounts, using a series of concentrations on the straight part of the curve, indicated that at 6 hours after LPS exposure, the lower chamber contains $118.10 \pm 7.3 \mathrm{ng}$ DNP-BSA $/ 100 \mu \mathrm{l}$ medium, while at $48 \mathrm{~h}, 164.63 \pm 12.4 \mathrm{ng}$ DNP-BSA/100 $\mu \mathrm{l}$ medium, significant increase over the control levels estimated at 10.1 $\pm 0.9 \mathrm{ng}$ DNP-BSA $/ 100 \mu \mathrm{l}$ medium, Figure $5 \mathrm{C}$. The findings are consistent with endothelial barrier dysfunction, gap formation and DNP-BSA leakage, as result of LPS exposure.

\section{Induction and activation of iNOS and a mitochondrial variant by LPS exposure}

Expression iNOS in response to LPS has been reported for several cell types such as epithelial cells, fibroblasts, hepatocytes, ECs [28,29]. A mitochondrial NOS, mtNOS, constitutively expressed, continuously active and associated with the inner mitochondrial membrane has been reported [21,30]. LPS-induced up-regulation of mitochondrial NO is one of the specific means, however still enigmatic, by which a dysfunctional and potentially pro-apoptotic environment is generated during the proinflammatory response in many cell types [31-33]. Thus, to evaluate the expression of iNOS and mtNOS in LPSexposed human lung microvascular ECs, we first investigated by immunoblotting the expression of iNOS in control and LPS-treated ECs (Figure 6A). We detected weak iNOS immuno-reactivity under control conditions, and it increases by $27 \%$, at $24 \mathrm{~h}$ and by $75 \%$ at 48 hours post LPS exposure (Figure 6B). Next, we investigated the effects of LPS on mtNOS expression. To this intent, mitochondria-enriched fractions prepared from these cells were lysed and subjected to SDS-PAGE. Even if mtNOS is constitutively expressed, the levels seem to be low, since no iNOS immunoreactivity was detected in 


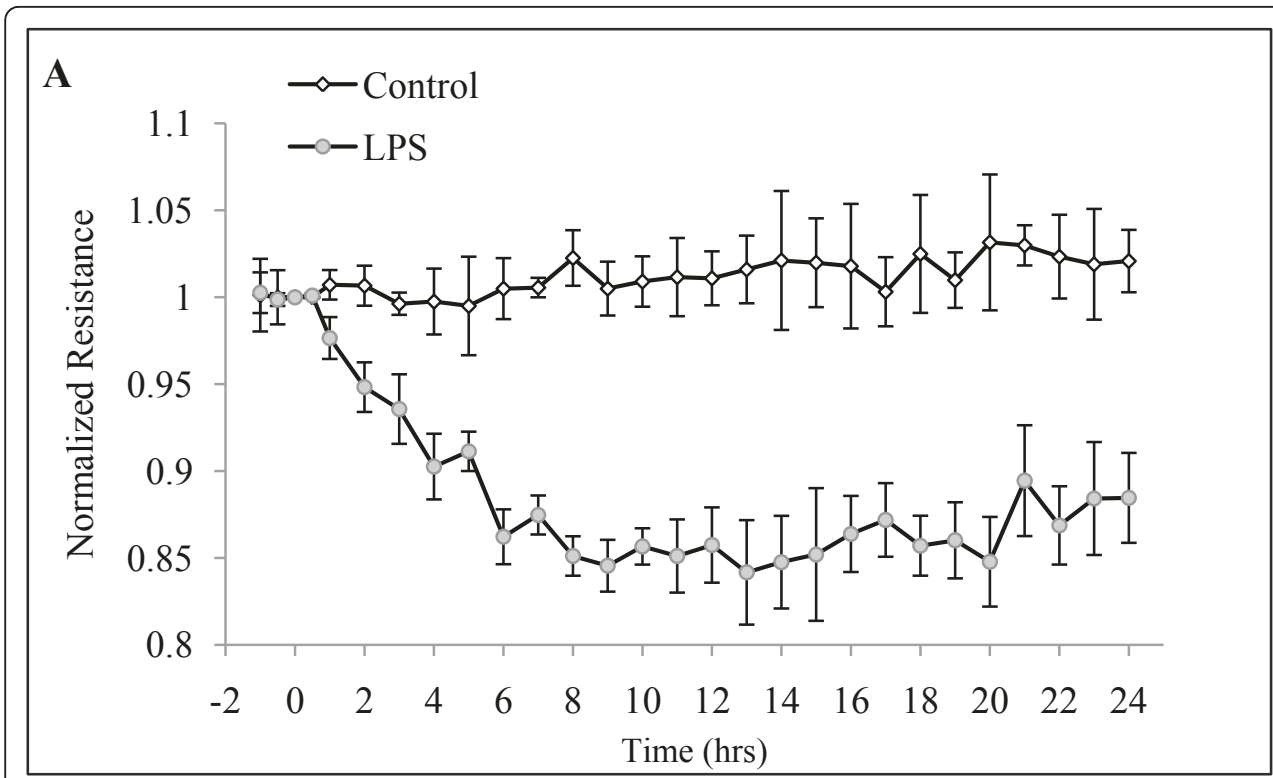

\section{$\mathbf{B}$}

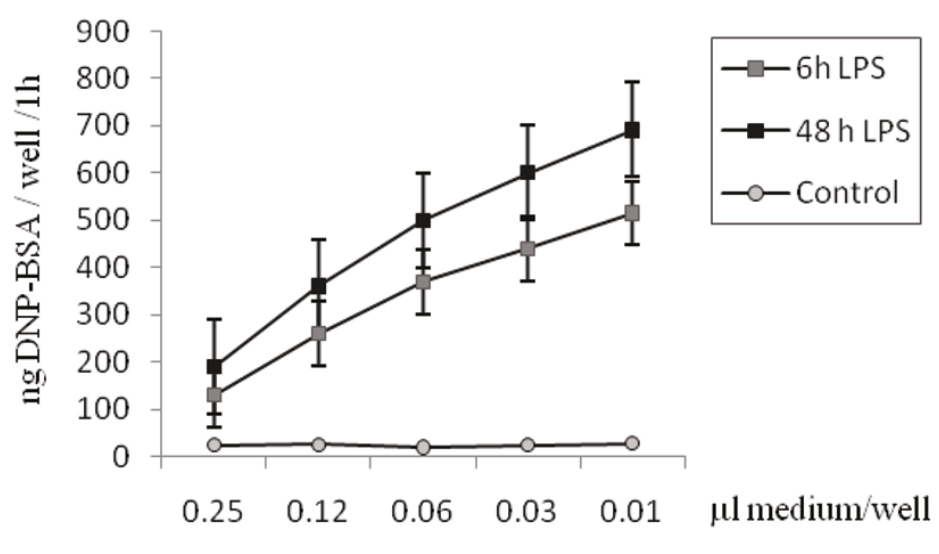

C

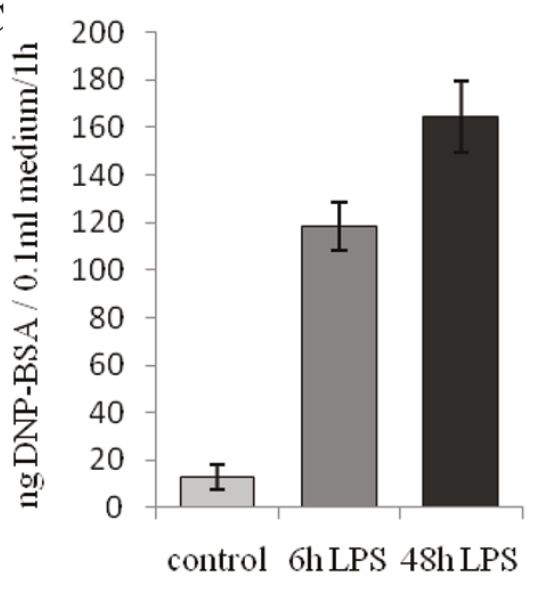

Figure $51 \mu \mathrm{g} / \mathrm{ml}$ LPS exposure causes endothelial barrier dysfunction. A. At the time point indicated (arrow), ECs grown on gold microelectrodes, were exposed to $1 \mathrm{\mu g} / \mathrm{ml}$ LPS, and TER was monitored over time. Data are expressed as means \pm SD of 3 independent experiments; $\mathrm{n}=3$ per condition for each experiment. DNP-BSA concentrations detected in growth media collected from the lower chamber in control vs. LPS-treated ECs. Tracer amounts were determined by ELISA in 3 independent experiments, $n=3$ per condition for each experiment. Ordinate, amounts of DNP-BSA detected per well; abscissa, $\mu \mathrm{l}$ growth medium per well. Degree of DNP-BSA leakage in LPS-treated ECs monolayer by reference to controls. Values are means \pm SD $\mathrm{ng}$ DNP-BSA/0.1 ml growth medium/1 hour.

the absence of LPS and under experimental conditions used (Figure 6C). However, in the mitochondrial fraction prepared from LPS-exposed ECs, mtNOS protein expression is easily detected, at 48 hours of LPS exposure (Figure 6C). Next, we addressed if the increased expression of mtNOS resulted in increased NO production. mtNOS activity was assessed by exposing freshly prepared, unlysed mitochondrial fractions from ECs to oxyHb, as described under Methods. The rate of NO production was measured by the change in optical density of the reaction mixture as generated NO quickly oxidized oxyHb to metHb. As shown in Figure 6D, mitochondria from LPS-treated ECs exhibited a two-fold greater rate of $\mathrm{NO}$ formation than untreated controls $(0.81 \mathrm{nmol} / \mathrm{min} \mathrm{mg}$ total protein versus $0.40 \mathrm{nmol} / \mathrm{min}$ mg total protein).

ITSN-1s protein and mRNA levels are markedly decreased after LPS exposure

We have recently shown that specific and efficient ITSN-1s knockdown via a specific siRNA duplex targeting ITSN-1 gene results in severe EC dysfunction and apoptotic death, events that can be reversed by overexpression of the anti-apoptotic Bcl- $\mathrm{X}_{\mathrm{L}}[7]$. 


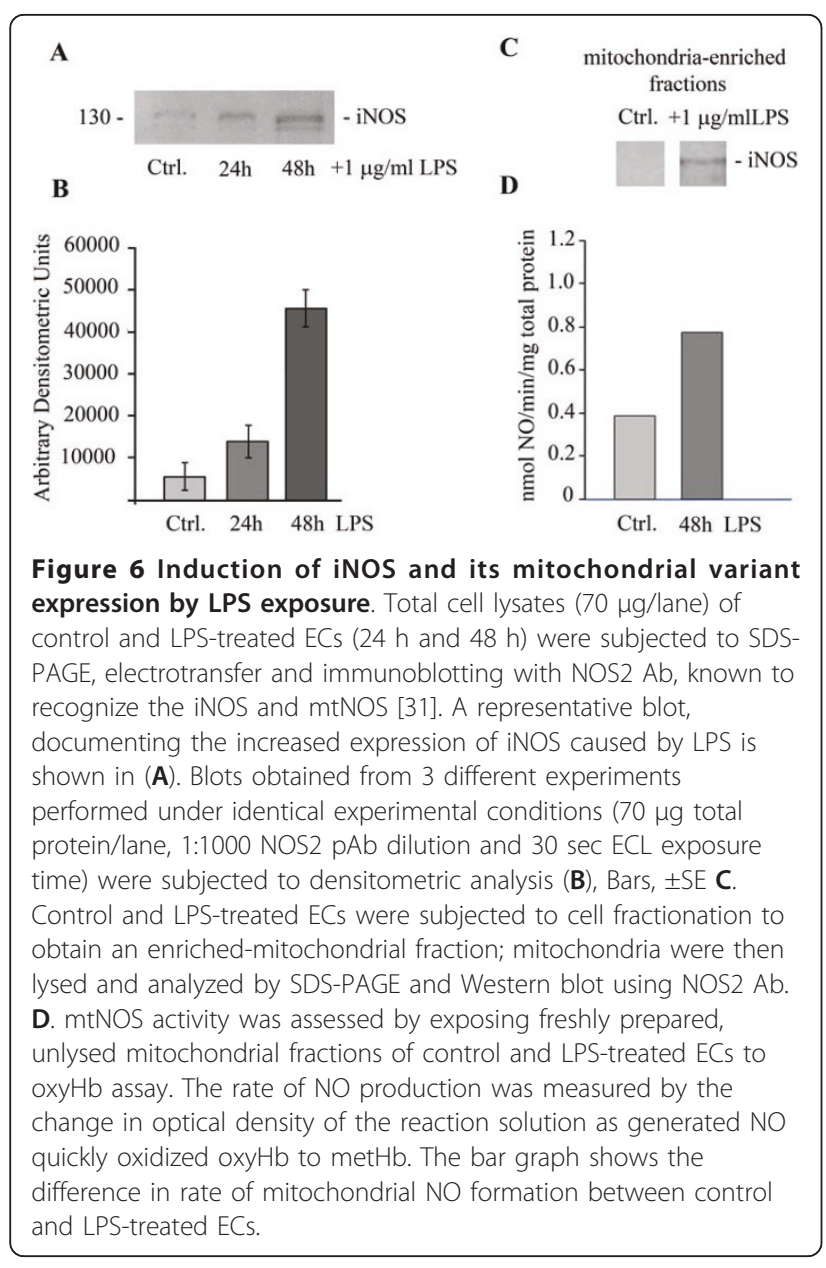

Previous studies of LPS-induced endothelial dysfunction suggested the ability of LPS to induce pro-apoptotic pathways [34] as well as a role of Bcl- $\mathrm{X}_{\mathrm{L}}$ in cytoprotection during inflammatory stress [3]. These observations led us to consider ITSN-1s as a participant in either of these events. We therefore evaluated the levels of ITSN-1s protein in lysates prepared from LPS-treated and control ECs by immunoblotting with ITSN-1 pAb. The $140 \mathrm{kDa}$ band representing ITSN-1s begins to decrease in intensity at $24 \mathrm{~h}$ and remains significantly decreased at $48 \mathrm{~h}$ after LPS exposure (Figure 7A). We also evaluated the level of ITSN-1s mRNA expression by quantitative PCR in ECs exposed to 1 $\mu \mathrm{g} / \mathrm{ml}$ LPS for 24 or 48 hours. ITSN-1s mRNA levels were dramatically reduced in LPS-exposed ECs compared to control cells (Figure 7B). ITSN-1s mRNA expression was reduced 4.3 -fold at 24 hours and 3.2fold at 48 hours of LPS treatment compared to untreated controls. These results are consistent with the idea that LPS down-regulates the expression of the pro-survival protein ITSN-1s; ITSN-1s deficiency may be relevant to ECs dysfunction induced by LPS.
Lung ECs do not undergo apoptosis in response to LPS Since LPS-exposed ECs show decreased mRNA levels for ITSN-1s and since ITSN-1s deficiency is expected to initiate intrinsic apoptosis, we evaluated the occurrence of apoptosis in cells treated with LPS for $48 \mathrm{~h}$, by TUNEL, Figure 7C, c1. Morphological surveys and morphometric analyzes show that the number of TUNELpositive ECs is extremely low, comparable to untreated ECs (Figure 7D). A positive control, in which cells were subjected to ITSN-1s knockdown by siRNA as in our previous work [7], is shown in Figure 7C, c2. A complementary strategy to evaluate if mitochondrial cell death occurred was the examination of cyt c efflux from mitochondria. An enriched-mitochondrial fraction and the post-mitochondrial supernatant prepared from LPS-treated ECs normalized for total protein content were subjected to SDS-PAGE and Western blot with cyt c mAb. No immunoreactivity for cyt $\mathrm{c}$ was detected in the postmitochondrial supernatant, consistent with cyt c confinement to mitochondria (Figure 7E). The findings suggest that ITSN-1s down-regulation as caused by LPS exposure of ECs did not trigger the intrinsic apoptotic pathway and suggest that LPS induces a cyto-protective response.

\section{LPS directly induces $\mathrm{BCl}-\mathrm{X}_{\mathrm{L}}$ and survivin expression, as well as down-regulation of the "BH3 only" Bim expression}

The protective effects of $\mathrm{Bcl}-\mathrm{X}_{\mathrm{L}}$ overexpression against LPS and ITSN-1s deficiency-induced cell death were previously documented [3,7]. However, whether LPS can directly induce $\mathrm{Bcl}-\mathrm{X}_{\mathrm{L}}$ expression has not been reported for human lung microvascular ECs. To determine whether LPS up-regulates the mRNA for Bcl- $\mathrm{X}_{\mathrm{L}}$, ECs were exposed to LPS for different time points (24 $\mathrm{h}, 48 \mathrm{~h}$ ), and the levels of $\mathrm{Bcl}-\mathrm{X}_{\mathrm{L}}$ protein and mRNA were determined (Figure 8). At $24 \mathrm{~h}$, the levels of Bcl$\mathrm{X}_{\mathrm{L}}$ are increased by 1.3 -fold, while at $48 \mathrm{~h}$ a significant, 3.4 fold-increase, compared to controls is detected. Thus, LPS can up-regulate the mRNA for this cyto-protective protein. Levels of $\mathrm{Bcl}-\mathrm{X}_{\mathrm{L}}$ protein correspond to mRNA accumulation. Interestingly, ECs deficient in ITSN-1s show decreased Erk1/2 activation [7]. Erk $1 / 2$ activation is responsible for constitutive phosphorylation of the pro-apoptotic "BH3 only" protein Bim, at $\mathrm{Ser}^{69}$ leading to proteasomal degradation [35-37]. Thus, it is possible that down-regulation of Bim may be another possible mechanism by which ECs cyto-protection occurs in response to LPS. To determine whether LPS affects the levels of phospho-Bim $\left(\mathrm{Ser}^{69}\right)$, control and LPS-treated ECs were solubilized in kinase buffer; equal amounts of total protein were subjected to SDS-PAGE and Western blot with a specific phospho-Bim $\left(\mathrm{Ser}^{69}\right)$ Ab. Total Bim was detected 


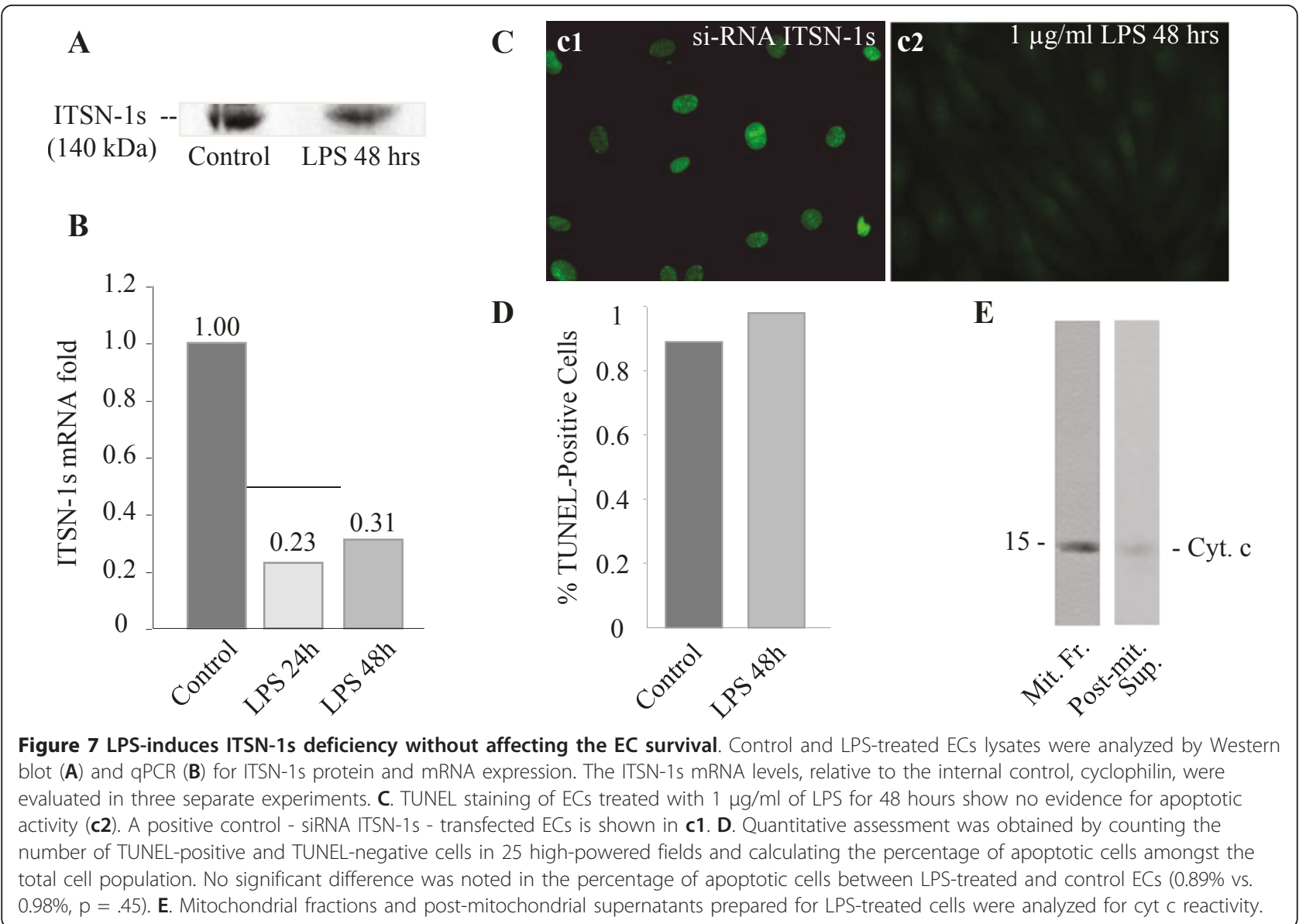

with a specific anti-Bim pAb (Figure 8). Substantial decrease in both $\mathrm{P}$-Bim $\left(\operatorname{Ser}^{69}\right)$ and total Bim was noted. Next, qPCR for mRNA levels were performed; in response to LPS exposure, Bim mRNA was dramatically reduced, 11 -fold compared to untreated controls at 24 hours and recovered to 1.2 -fold reduction at 48 hours (Figure 8). These studies are consistent with the idea that down-regulation of Bim, as well as up-regulation of $\mathrm{Bcl}-\mathrm{X}_{\mathrm{L}}$ serve as cyto-protective pathways against LPS-induced apoptosis in lung microvascular ECs.

Since Bim down-regulation was linked to the overexpression of survivin, an inhibitor of apoptosis protein, [38] and since LPS-induced NF-kB signaling may regulate survivin expression [39], we next examined by Western blot and qPCR the effects of LPS on survivin expression. As shown in Figure 8, survivin mRNA levels increased 5.2-fold in the first $24 \mathrm{~h}$ and remained increased by 4.2 -fold at $48 \mathrm{~h}$. The relative increase in survivin protein levels was confirmed by Western blot (Figure 8). The observation further documents that survivin up-regulation is another anti-apoptotic effect induced by LPS in ECs.

\section{Expression of myc-ITSN-1s in LPS-treated ECs restores endocytosis and inhibits LPS signaling}

Since cav-1 is a potential molecular chaperone that directly inactivates all NOS isoforms [40], and since ITSN-1s down-regulation inhibits caveolae internalization and thereby, increases LPS signaling [25], we sought to investigate if restoring endocytosis by ectopic expression of myc-ITSN-1s can affect iNOS expression. To this intent, subconfluent ECs monolayers, exposed to LPS for $48 \mathrm{~h}$, were transfected with myc tagged fulllength ITSN-1s, as previously described [15]. Efficient ITSN-1s expression was detected at $48 \mathrm{~h}$ post-transfection by immunoblotting of ECs lysates with anti-myc Ab, Figure 9C. Next, ECs grown on coverslips and exposed to LPS for $48 \mathrm{~h}$, were transfected with mycITSN-1s and subjected to the biotin internalization assay. Fluorescent microscopy analyses of internalized biotin via neutrAvidin AlexaFluor 594 staining indicated that most of the cells display a fine punctate pattern staining (Figure 9A, a2, a3) similar to control cells (Figure 9A, a1), suggestive of biotin internalization via caveolae. Biochemical quantification of biotin molecules in lysate prepared from LPS-treated/ITSN-1s-transfected 


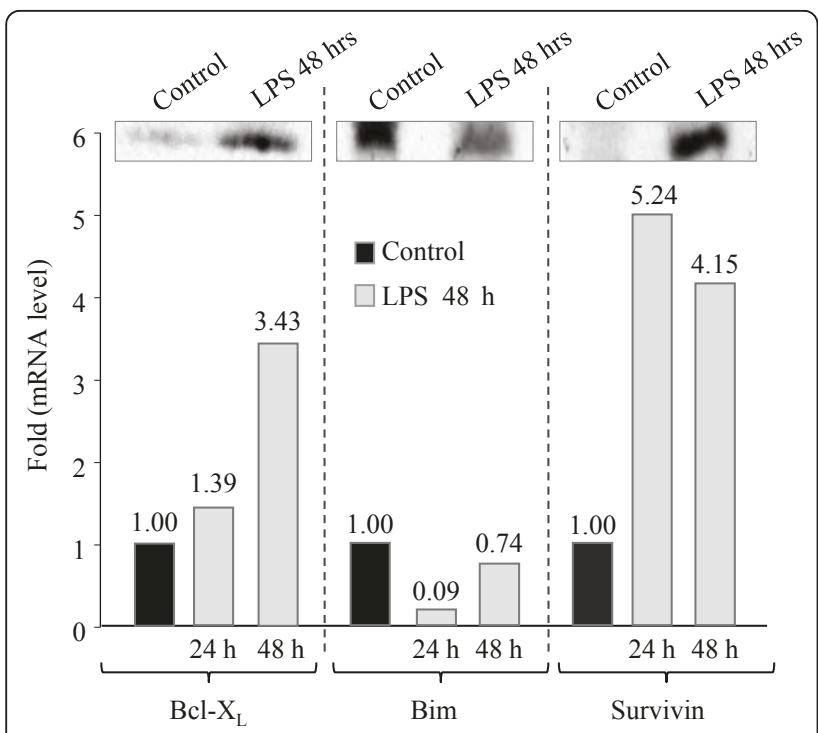

Figure 8 Control and LPS-treated cell lysates ( $24 \mathrm{~h}, 48 \mathrm{~h}$ ) were also analyzed by $\mathrm{qPCR}$ for mRNA expression of $\mathrm{Bim}, \mathrm{Bcl}-\mathrm{X}_{\mathrm{L}}$ and survivin, relative to the internal control, cyclophilin, in three separate experiments. Representative results of one of these experiments are shown. Total protein concentration in control and LPS-treated cell lysates was determined by BCA, and $80 \mu \mathrm{g}$ of total protein per sample was subjected to SDS-PAGE. Gels transferred to nitrocellulose membranes were then probed with $\mathrm{BCl}-\mathrm{XL}$, Bim and survivin Abs. These trends were confirmed in at least three separate experiments for each protein.

cells shows that these ECs significantly recovered their ability to internalize biotin, when compared to untreated cells (Figure 9B). Less than 25\% inhibition of biotin internalization, still detected after myc-ITSN-1s expression, can be explained by the incomplete transfection of the entire ECs population. For the same reason, evaluation of the effects of ITSN-1s rescue on paracellular permeability is methodologically limited.

To evaluate the effects of myc-ITSN-1s expression and effective endocytosis on iNOS expression, we prepared total cell lysates from control, LPS-treated and LPS-treated/ITSN-1s-transfected ECs; equivalents of total protein amounts were analyzed by SDS-PAGE, electrotransfer to nitrocellulose membranes and western blot using NOS2 Ab. LPS-treated/ITSN-1s-transfected ECs show lower immunoreactivity to NOS-2 Ab and thereby, lower expression of iNOS, by comparison to LPS-treated ECs (no ITSN-1s transfection), Figure 9C. Then, the effects of myc-ITSN-1s expression on mtNOS in LPS-exposed ECs, were analyzed on mitochondrial-enriched fractions prepared from control, LPS-treated and LPS-treated/ ITSN-1s-transfected ECs; mitochondrial lysates were normalized for total protein content and analyzed by SDS-PAGE, electrotransfer to nitrocellulose membranes and western blot using NOS2 Ab. As shown in Figure 9D, mtNOS is detected in the mitochondria fraction prepared from LPS-treated ECs. No NOS2 immunoreactivity was detected in control or LPS-treated/ITSN-1stransfected ECs. The observation is consistent with the idea that ITSN-1s deficiency and the resultant impaired caveolae internalization is relevant to ECs response to inflammatory stimuli.

\section{Conclusions}

Vascular barrier dysfunction contributes to the clinical hallmark of lung injury [41]. Transport of plasma proteins and solutes across the endothelium involves a cross-talk between the transcellular route via caveolae and the paracellular route through IEJs, $[27,42]$. In a previous study, when caveolae transcytosis was disrupted by cav-1 knockdown, the IEJs opened and a protein-rich interstitial edema reminiscent of LPS-induced lung injury developed [43]. Interestingly, treatment with the NOS inhibitor, L-NAME, reversed the effects of cav-1 knockdown on junctional hyperpermeability.

Our current observations of LPS-induced ITSN-1s down-regulation and subsequent endocytic traffic dysfunction and disruption of IEJs support the established cross-link between the transcellular and paracellular transport pathways and suggest a possible mechanism by which NO mediates this coupling is via NOS-2 activation and its association with mitochondria.

Our data also show that during LPS-induced ITSN-1s down-regulation, ECs do not undergo apoptosis as occurs when these cells are depleted of ITSN-1s via a specific siRNA duplex targeting ITSN-1s gene [7]. Furthermore, in our study we found that ECs may be protected from apoptosis by the compensatory LPSmediated down-regulation of pro-apoptotic Bim and upregulation of anti-apoptotic $\mathrm{Bcl}-\mathrm{X}_{\mathrm{L}}$ and survivin. These observations are in line with previous studies indicating that human ECs undergo apoptosis in response to LPS only when protein synthesis is inhibited. Induced cytoprotection maintains ECs in a state of activated dysfunction which may perpetuate their critical contribution to the mechanisms of lung injury. Indeed, studies in animal models and human patients with lung injury have shown that apoptosis may be a prerequisite to the resolution of inflammation and initiation of repair [44,45]. One of the keys to advancing recovery in lung injury may therefore lie in understanding the transition between the dysfunctional, cyto-protective phenotype described here and the onset of programmed cell death.

Altogether, our studies established the role of the endocytic protein, ITSN-1s, as a novel node in LPS-EC signaling and offer interesting insights into the 


\section{A}
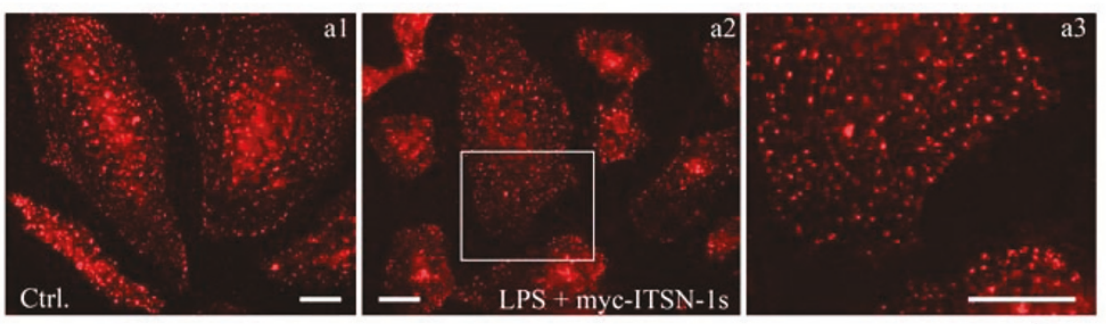

B

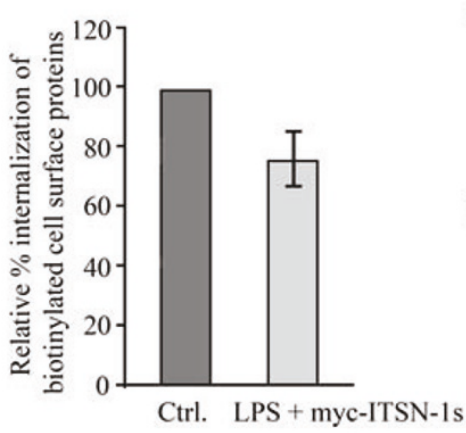

C

myc-ITSN-1s iNOS actin

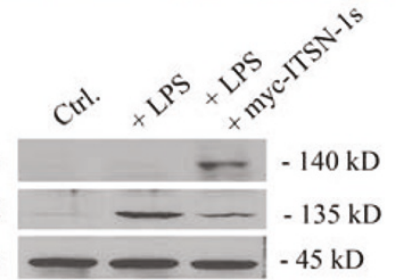

D

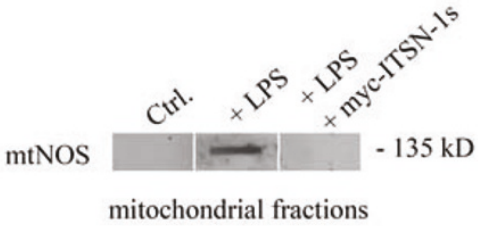

Figure 9 Expression of myc-ITSN-1s in LPS-treated ECs restores endocytosis and inhibits both iNOS and mtNOS protein expression. A Myc-ITSN-1s-transfected ECs, 48 h post-transfection, were exposed to $1 \mu \mathrm{g} / \mathrm{ml}$ LPS cells for $48 \mathrm{~h}$ and then subjected to biotin internalization. NeutrAvidin Alexa Fluor 594 staining revealed the rescued ability of ECs to internalized biotin (a2). An enlarged region of interest (boxed area in a2) is shown in a3. Control ECs subjected to biotin internalization and NeutrAvidin Alexa Fluor 594 are shown for comparison in a1. Bars: a1, a2, a3 - $20 \mu \mathrm{m}$. B. Degree of inhibition of caveolae-mediated uptake in myc-ITSN-1s transfected and LPS-treated ECs, by comparison to controls was evaluated by ELISA in 3 different experiments. Bars, \pm SD. C. Total ECs lysates (70 $\mu \mathrm{g}$ total protein/lane) prepared from control, LPS-treated and ITSN-1s transfected and LPS-treated cells were analyzed by SDS-PAGE, electrotransfer to nitrocellulose membranes and Western blotting for NOS2 protein expression. Actin was used as loading control. D. Enriched-mitochondrial fractions of control, LPS-treated and myc-ITSN-1s transfected/LPS-treated cells were analyzed as above for mtNOS expression.

significance of endocytic dysfunction, mitochondrial NO production, cyto-protection, and the potential relationships between these systems in ECs during LPS-induced lung injury.

\section{List of Abbreviations}

EC: human lung microvascular endothelial cell; ITSN-1 s: intersectin 1-short; EM: electron microscopy; cyt c: cytochrome c; cav-1: caveolin-1; iNOS: inducible nitric oxide synthase; LPS: lipopolysaccharide; IEJ: interendothelial junction; mtNOS: mitochondrial nitric oxide synthase; DNP-BSA: dinitrophenylated bovine serum albumin; TER: transendothelial electrical resistance.

\section{Acknowledgements}

We are grateful to Dr. Suzana de la Luna, (Center for Genomic Regulation, UPF, and Centro de Investigacion Biomedica en Red de Enfermedades Raras, Barcelona, Spain) for providing ITSN-1 CDNA. This work was supported by National Institute of Health Grants R01HL089462-01 and start-up funds from Rush University (to S.P.), the New Investigator Award, Rush University Medical Center, and a private donation from Mr. and Mrs. Richard D. Jaffee, (to S.S.)

\section{Author details}

'Pulmonary and Critical Care Medicine, Rush University Medical Center, 1750 W. Harrison Street, 297 Jelke, Chicago, IL 60612, USA. ${ }^{2}$ Department of
Pharmacology, Rush University, 1735 W. Harrison Street, 1537 Jelke, Chicago, IL 60612, USA.

\section{Authors' contributions}

SS and SP conceived of the study, designed the experiments, and drafted the manuscript. DP performed the electron microscopy, TER measurements, and assisted in experimental design throughout the study. SS and CB performed the Western blotting, and immunofluorescence studies. CB carried out the ELISA for the biotin internalization and DNP-BSA assays. MW generated the ITSN-1S construct and JZ designed the primers for and carried out the quantitative PCR experiments. RAB participated in coordinating the study and helped draft the manuscript. All authors read and approved the final manuscript.

\section{Competing interests}

The authors declare that they have no competing interests.

Received: 3 January 2011 Accepted: 12 April 2011

Published: 12 April 2011

\section{References}

1. Rubenfeld GD, Caldwell E, Peabody E, Weaver J, Martin DP, Neff M, Stern EJ, Hudson LD: Incidence and outcomes of acute lung injury. N Engl J Med 2005, 353:1685-1693.

2. Bannerman DD, Tupper JC, Ricketts WA, Bennett CF, Winn RK, Harlan JM: A constitutive cytoprotective pathway protects endothelial cells from lipopolysaccharide-induced apoptosis. J Biol Chem 2001, 276:14924-14932. 
3. Wang HL, Akinci IO, Baker CM, Urich D, Bellmeyer A, Jain M, Chandel NS, Mutlu GM, Budinger GR: The intrinsic apoptotic pathway is required for lipopolysaccharide-induced lung endothelial cell death. J Immuno/ 2007, 179:1834-1841.

4. Pober JS, Sessa WC: Evolving functions of endothelial cells in inflammation. Nat Rev Immunol 2007, 7:803-815.

5. Bierhaus A, Chen J, Liliensiek B, Nawroth PP: LPS and cytokine-activated endothelium. Semin Thromb Hemost 2000, 26:571-587.

6. Ding J, Song D, Ye X, Liu SF: A pivotal role of endothelial-specific NFkappaB signaling in the pathogenesis of septic shock and septic vascular dysfunction. J Immunol 2009, 183:4031-4038.

7. Predescu SA, Predescu DN, Knezevic I, Klein IK, Malik AB: Intersectin-1s regulates the mitochondrial apoptotic pathway in endothelial cells. J Biol Chem 2007, 282:17166-17178.

8. Knezevic I, Predescu D, Bardita C, Wang M, Sharma T, Keith B, Neamu R, Malik A, Predescu S: Regulation of Dynamin-2 Assembly-Disassembly and Function Through the SH3A Domain of Intersectin-1s. J Cell Mol Med 2010.

9. Boueiz A, Hassoun PM: Regulation of endothelial barrier function by reactive oxygen and nitrogen species. Microvasc Res 2009, 77:26-34.

10. Guo RF, Ward PA: Role of oxidants in lung injury during sepsis. Antioxid Redox Signal 2007, 9:1991-2002.

11. Aird WC: The role of the endothelium in severe sepsis and multiple organ dysfunction syndrome. Blood 2003, 101:3765-3777.

12. Kristof AS, Goldberg P, Laubach V, Hussain SN: Role of inducible nitric oxide synthase in endotoxin-induced acute lung injury. Am J Respir Crit Care Med 1998, 158:1883-1889.

13. Wang le F, Patel M, Razavi HM, Weicker S, Joseph MG, McCormack DG, Mehta S: Role of inducible nitric oxide synthase in pulmonary microvascular protein leak in murine sepsis. Am J Respir Crit Care Med 2002, 165:1634-1639.

14. Schubert W, Frank PG, Woodman SE, Hyogo H, Cohen DE, Chow CW, Lisanti MP: Microvascular hyperpermeability in caveolin-1 (-/-) knock-out mice. Treatment with a specific nitric-oxide synthase inhibitor, L-NAME, restores normal microvascular permeability in Cav-1 null mice. J Biol Chem 2002, 277:40091-40098.

15. Predescu SA, Predescu DN, Timblin BK, Stan RV, Malik AB: Intersectin regulates fission and internalization of caveolae in endothelial cells. $\mathrm{Mol}$ Biol Cell 2003, 14:4997-5010

16. Klein IK, Predescu DN, Sharma T, Knezevic I, Malik AB, Predescu S: Intersectin-2L regulates caveola endocytosis secondary to $\mathrm{Cdc} 42$ mediated actin polymerization. J Biol Chem 2009, 284:25953-25961.

17. Savage MD: Avidin-biotin chemistry: a handbook Rockford, IL: Pierce Chemical Co; 1992

18. Xing J, Birukova AA: ANP attenuates inflammatory signaling and Rho pathway of lung endothelial permeability induced by LPS and TNFalpha. Microvasc Res 2010, 79:56-62.

19. Predescu D, Horvat R, Predescu S, Palade GE: Transcytosis in the continuous endothelium of the myocardial microvasculature is inhibited by N-ethylmaleimide. Proc Natl Acad Sci USA 1994, 91:3014-3018.

20. Predescu SA, Predescu DN, Palade GE: Plasmalemmal vesicles function as transcytotic carriers for small proteins in the continuous endothelium. Am J Physiol 1997, 272:H937-949.

21. Ghafourifar P, Asbury ML, Joshi SS, Kincaid ED: Determination of mitochondrial nitric oxide synthase activity. Methods Enzymol 2005, 396:424-444.

22. Dixon HB, Mclntosh R: Reduction of methaemoglobin in haemoglobin samples using gel filtration for continuous removal of reaction products. Nature 1967, 213:399-400

23. Dauphinee SM, Karsan A: Lipopolysaccharide signaling in endothelial cells. Lab Invest 2006, 86:9-22.

24. Hopkins CR, Gibson A, Shipman M, Miller K: Movement of internalized ligand-receptor complexes along a continuous endosomal reticulum. Nature 1990, 346:335-339.

25. Husebye $H$, Halaas O, Stenmark $H$, Tunheim G, Sandanger O, Bogen B, Brech A, Latz E, Espevik T: Endocytic pathways regulate Toll-like receptor 4 signaling and link innate and adaptive immunity. EMBO J 2006, 25:683-692.

26. Shuto T, Kato K, Mori Y, Viriyakosol S, Oba M, Furuta T, Okiyoneda T, Arima H, Suico MA, Kai H: Membrane-anchored CD14 is required for LPS- induced TLR4 endocytosis in TLR4/MD-2/CD14 overexpressing CHO cells. Biochem Biophys Res Commun 2005, 338:1402-1409.

27. Predescu SA, Predescu DN, Malik AB: Molecular determinants of endothelial transcytosis and their role in endothelial permeability. Am $J$ Physiol Lung Cell Mol Physiol 2007, 293:L823-842.

28. Bogdan C: Nitric oxide and the regulation of gene expression. Trends Cell Biol 2001, 11:66-75

29. Geiger M, Stone A, Mason SN, Oldham KT, Guice KS: Differential nitric oxide production by microvascular and macrovascular endothelial cells. Am J Physiol 1997, 273:L275-281.

30. Ghafourifar $P$, Richter C: Nitric oxide synthase activity in mitochondria. FEBS Lett 1997, 418:291-296.

31. Lopez LC, Escames G, Tapias V, Utrilla P, Leon J, Acuna-Castroviejo D: Identification of an inducible nitric oxide synthase in diaphragm mitochondria from septic mice: its relation with mitochondrial dysfunction and prevention by melatonin. Int J Biochem Cell Biol 2006, 38:267-278.

32. Lisdero CL, Carreras MC, Meulemans A, Melani M, Aubier M, Boczkowski J, Poderoso JJ: The mitochondrial interplay of ubiquinol and nitric oxide in endotoxemia. Methods Enzymol 2004, 382:67-81.

33. Titheradge MA: Nitric oxide in septic shock. Biochim Biophys Acta 1999 1411:437-455

34. Hu X, Yee E, Harlan JM, Wong F, Karsan A: Lipopolysaccharide induces the antiapoptotic molecules, $\mathrm{A} 1$ and $\mathrm{A} 20$, in microvascular endothelial cells. Blood 1998, 92:2759-2765.

35. Harada H, Quearry B, Ruiz-Vela A, Korsmeyer SJ: Survival factor-induced extracellular signal-regulated kinase phosphorylates BIM, inhibiting its association with BAX and proapoptotic activity. Proc Natl Acad Sci USA 2004, 101:15313-15317.

36. Ewings KE, Hadfield-Moorhouse K, Wiggins CM, Wickenden JA, Balmanno K, Gilley R, Degenhardt K, White E, Cook SJ: ERK1/2-dependent phosphorylation of BimEL promotes its rapid dissociation from $\mathrm{Mcl}-1$ and $\mathrm{BCl}-\mathrm{xL}$. EMBO J 2007, 26:2856-2867.

37. Ley R, Ewings KE, Hadfield K, Howes E, Balmanno K, Cook SJ: Extracellular signal-regulated kinases $1 / 2$ are serum-stimulated "Bim(EL) kinases" that bind to the $\mathrm{BH} 3$-only protein Bim(EL) causing its phosphorylation and turnover. J Biol Chem 2004, 279:8837-8847.

38. Romagnoli M, Seveno C, Wuilleme-Toumi S, Amiot M, Bataille R, Minvielle S, Barille-Nion S: The imbalance between Survivin and Bim mediates tumour growth and correlates with poor survival in patients with multiple myeloma. Br J Haematol 2009, 145:180-189.

39. Ichikawa H, Takada Y, Murakami A, Aggarwal BB: Identification of a novel blocker of I kappa B alpha kinase that enhances cellular apoptosis and inhibits cellular invasion through suppression of NF-kappa B-regulated gene products. J Immunol 2005, 174:7383-7392.

40. Garcia-Cardena G, Martasek P, Masters BS, Skidd PM, Couet J, Li S, Lisanti MP, Sessa WC: Dissecting the interaction between nitric oxide synthase (NOS) and caveolin. Functional significance of the nos caveolin binding domain in vivo. J Biol Chem 1997, 272:25437-25440.

41. Sinclair D, Braude S, Haslam P, Evans T: Pulmonary endothelial permeability in patients with severe lung injury. Clinical correlates and natural history. Chest 1994, 106:535-539.

42. Komarova Y, Malik AB: Regulation of endothelial permeability via paracellular and transcellular transport pathways. Annu Rev Physiol 72:463-493.

43. Miyawaki-Shimizu K, Predescu D, Shimizu J, Broman M, Predescu S, Malik AB: siRNA-induced caveolin-1 knockdown in mice increases lung vascular permeability via the junctional pathway. Am J Physiol Lung Cell Mol Physiol 2006, 290:L405-413.

44. Huynh MLFV, Henson PM: Phosphatidylserine-dependent ingestion of apoptotic cells promotes TGF-beta1 secretion and the resolution of inflammation. J Clin Invest 2002, 109:41-50.

45. Polunovsky VACB, Henke C, Snover D, Wendt C, Ingbar DH, Bitterman PB: Role of mesenchymal cell death in lung remodeling after injury. J Clin Invest 1993, 92:388-397.

doi:10.1186/1465-9921-12-46

Cite this article as: Singla et al: Pro-inflammatory endothelial cell dysfunction is associated with intersectin-1s down-regulation. Respiratory Research 2011 12:46. 